\title{
Role of Ultrasound and Color Doppler in Assessment of Incidental Thyroid Nodules
}

\author{
Hesham E. Elsheikh, Ahmed E. Shalaan, Doaa ELsebaey
}

\begin{abstract}
Department of Radiology, Benha faculty of medicine, Benha University, Egypt.

Correspondence to: Doaa ELsebaey, Department of Radiology, Benha faculty of medicine, Benha University, Egypt.
\end{abstract}

Email:

doaasalembenha@gmail.com

Received: 16 June, 2020

Accepted: 22 June, 2020

\section{Abstract:}

Background: Important discovered of incidental thyroid nodules by different imaging like $\mathrm{CT}$ or MRI and examination of the nodules by ultrasound to differentiate between the benign and malignant thyroid nodules and assess the vascularity of the nodules by color Doppler. Aim of work: The study was done to evaluate the role of US examination and color Doppler in assessment of incidental thyroid nodules Patient and methods: We evaluated 50 patients (by ultrasound and color Doppler) with 36 benign thyroid tumors, 14 malignant thyroid tumors. The ultrasound and color Doppler diagnosis was confirmed by histological examination. Results: In this study the US diagnosis was correlated with the final diagnosis based on histological examination in $92 \%$ of cases, 14 cases $28 \%$ were malignant and 32 cases $64 \%$ were benign. Conclusion: US is a valuable tool in assessment of incidentally detected thyroid nodules in others imaging features as it can show specific morphologic pattern in differentiating benign form malignant nodules. Ultrasonography can shorten the diagnosis time and reduce the burden on physicians. US diagnosis was correlated with the final diagnosis based on histological examination in most cases.

Keywords: Incidental findings, thyroid nodules, Ultrasound, Color Doppler.

\section{Introduction}

The incidental thyroid nodule (ITN) is one

of the most common incidental findings on imaging studies that include the neck. An ITN is defined as a nodule not previously detected or suspected clinically, but identified by an imaging study like MRI ,CT and US that performed for assessment other regions not involved the thyroid. 
The majority of ITNs are benign, and small, incidental thyroid malignancies typically have indolent behavior (1).

Sonographic features of incidental thyroid nodule can be useful to differentiate between benign and malignant nodules ,the benign criteria is well defined wall hyper echoic, peripheral vascularity and no calcification but the malignant criteria is solid, more hypo echoic, in addition, irregular margins, shape that was more tall than wide, an intranodular vascular pattern, or micro calcifications. Larger nodule size was not a risk factor for malignancy. Thus, using these criteria to select nodules for FNA (2).

Ultrasonography is the first choice for detecting thyroid abnormalities because of its safety, noninvasiveness, no radioactivity, and effectiveness and also can detect the presence, site, size ,shape, and number of thyroid nodules ,unilateral or bilateral, margin, echo structure ,echogenicity and calcification and can be detect characteristics of malignancy, such as ill-defined margin, irregular shape, hypo echogenicity, heterogeneity, absence of cystic lesion and/or the halo sign, the presence of calcification, and invasion to adjacent organs ( 3)
The ultrasound features in the ACR Thyroid Imaging, Reporting and Data System (TIRADS) are categorized as benign, minimally suspicious, moderately suspicious, or highly suspicious for malignancy (4)

Color Doppler imaging can assess the blood flow pattern in thyroid nodules, the flow pattern of the nodule divided in to 3 types, type 1 absence of blood flow, type 2 peri nodular and absent or slight intranodular blood flow and type 3 marked intranodular and absent or slight peri nodular blood flow (5).

\section{Patients and methods}

This prospective study was conducted between 12December 2018 to February 2020 on 50 patients with incidental thyroid nodules on different radiological imaging's like MRI, CT and US that performed for assessment other regions not involved the thyroid referred from outpatient clinics to the radiology department of Met Gamer oncology center and gave their informed consent and approval of ethics committee. Fifty patients had incidental thyroid nodules diagnosed by US and color Doppler. Patients with incidental thyroid nodules on different radiological imaging's like MRI, CT and US that performed for 
assessment other regions not involved the thyroid and these patients underwent ultrasound examination of the thyroid that confirmed the presence of thyroid nodule.

The study was approved by the ethical committee of Benha faculty of medicine. An informed written consent in Arabic language was obtained from all participants. It included all details about the study (title, objectives, methods, expected benefits and confidentiality data)

The use of high frequency probe which could help to localize pathological condition, to visualize the thyroid gland optimally, the patient is placed in the supine position with a pillow underneath the shoulders. The examination should be performed with the neck in hyperextension. The right and left lobes of the thyroid gland should be imaged in the longitudinal and transverse planes (6).

Ultrasound can detect the presence, site, size, and number of thyroid nodules, margin, echo structure, echogenicity and calcification, and can be detect characteristics of malignancy, such as illdefined margin, irregular shape, hypo echogenicity, heterogeneity, absence of cystic lesion and/or the halo sign, the presence of calcification, and invasion to adjacent organs (3).
Color Doppler examination, the patient was placed in the supine position with hyper extended the neck with avoid swallowing during the examination, using high frequency linear probe of 7-12MHZ. Color flow Doppler examination is performed with biplanar scanning. The amplifier gain is individually chosen in each case to be at a level immediately under the point of appearance of random color noise. Pulse repetition frequency was established at $500-750 \mathrm{~Hz}$, which is useful for slow flow evaluation. Vascularity pattern is evaluated using sagittal and transverse scans performed along the maximum diameter of the nodule (7).

\section{Results}

Fifty patients (42 females and 8 males) were included in this study. Their age ranged from 25 to 69 with a median age 45 years. The diagnosis was confirmed by histologic biopsy according to standard histo pathological procedures. Most patients were included in age group between (30-40 years) then between (40-50 years)

As regard age, the mean age of study population is 44.7 years. As regard gender, $16 \%$ of patients were males while $84 \%$ were females. 

Incidental nodule discovered in patients mostly doing CT chest 22 cases, 10 doing CT neck, 14 cases doing MRI and 4 doing neck US for LNS swelling.

Most patients presented by cough (18 cases), 6 patients presented by chest pain 10 patients presented by LNS swelling and 6 patients presented by hoarseness of voice 6 presented by fever and 4 presented others like difficult swallowing and dyspnea

From 50 thyroid nodules 36 were benign and 14 were malignant.

As regard ultrasound findings, we classified type of nodule as Solitary nodule, Multinodule and cystic nodule. Solitary solid nodule represented $(64 \%)$ of all patients, while Soild Multinodule was 12\% of all patients and cystic nodule/s was $24 \%$ of all patients, table1.

Table (1): type of thyroid nodule according to US

\begin{tabular}{lll}
\hline Type of nodule & $\mathbf{n}$ & \% \\
\hline Solitary solid nodule & 32 & 64 \\
Soild multinodule & 6 & 12 \\
Cystic nodule/s & 12 & 24 \\
\hline
\end{tabular}

As regard nodular outline, 36 cases showed regular nodular outline (72\%) while irregular or ill-defined outline represented in $14(28 \%$ ) patients (Table 2).
Table (2) type of nodular outline according to US

\begin{tabular}{lll}
\hline Nodular outline & n & \% \\
\hline Regular & 36 & 72 \\
Irregular or ill defined & 14 & 28 \\
\hline
\end{tabular}

Calcification was obtained in 24 case (52\%) which is divided to course or macro calcification (24\% of pt.) and micro calcification ( $28 \%$ of pt.) while $(48 \%)$ of thyroid nodules showed no calcification (Table 3 and figure 1)

Table ( 3 ) : type of calcification

\begin{tabular}{lll}
\hline Calcification & n & \% \\
\hline Macrocalcification & 12 & 24 \\
Microcalcification & 14 & 28 \\
No calcification & 24 & 48 \\
\hline
\end{tabular}

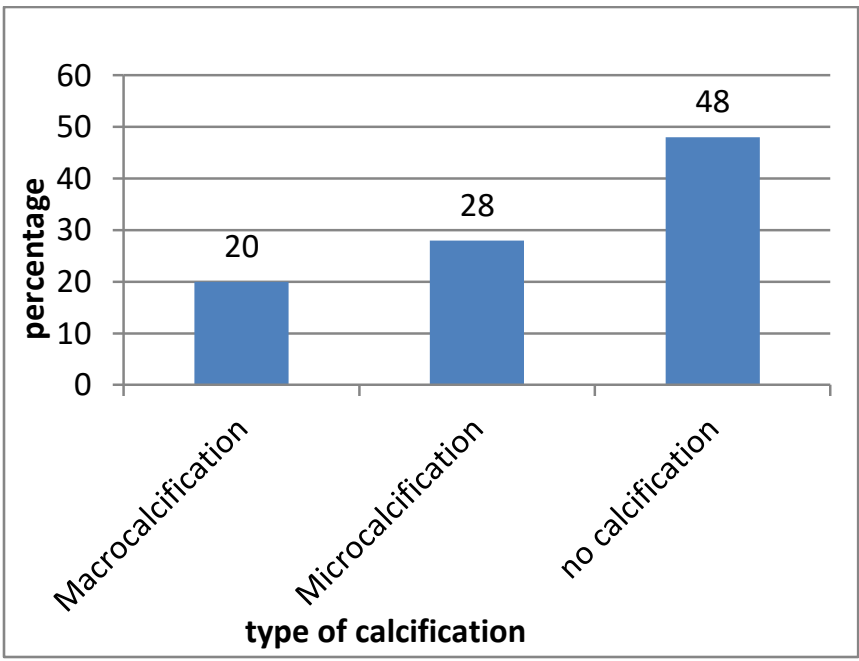

Fig: (1) show type of calcification 

The cytological diagnosis of ultrasoundguided fine needle aspiration biopsy of the thyroid was as the following : colloid cyst (24\%), papillary carcinoma (20\%), follicular adenoma (16\%), solitary nodular goiter (24\%), multi nodular goiter $(8 \%)$, medullary carcinoma (4\%), and follicular carcinoma (4\%). Table 4

Table (4) Cytological diagnosis

\begin{tabular}{lll}
\hline Cytological diagnosis & n & \% \\
\hline Colloid cyst & 12 & 24 \\
Papillary carcinoma & 10 & 20 \\
Follicular adenoma & 8 & 16 \\
Solitary nodular goiter & 12 & 24 \\
Multi nodular goiter & 4 & 8 \\
Medullary carcinoma & 2 & 4 \\
Follicular carcinoma & 2 & 4 \\
\hline
\end{tabular}

As regard doppler finding and its relation to malignancy confirmed by histopathological examination we found that all cases with malignant thyroid nodules showed increased central vascularity while benign tumors associated with decreased central vascularity in 20 from total 22 case, table 5

Table ( 5) doppler finding

\begin{tabular}{lll}
\hline & $\begin{array}{l}\text { Malignant } \\
\text { tumor }\end{array}$ & $\begin{array}{l}\text { Benign } \\
\text { tumor }\end{array}$ \\
\hline $\begin{array}{l}\text { increased central } \\
\text { vascularity } \\
\text { decreased central } \\
\text { vascularity }\end{array}$ & 14 & 2 \\
\hline
\end{tabular}

In this study the US diagnosis was correlated with the final diagnosis based on histological examination in $92 \%$ of cases, 14 cases $28 \%$ were malignant and 32 cases $64 \%$ were benign, figure 2

US diagnosis correlated with final diagnosis

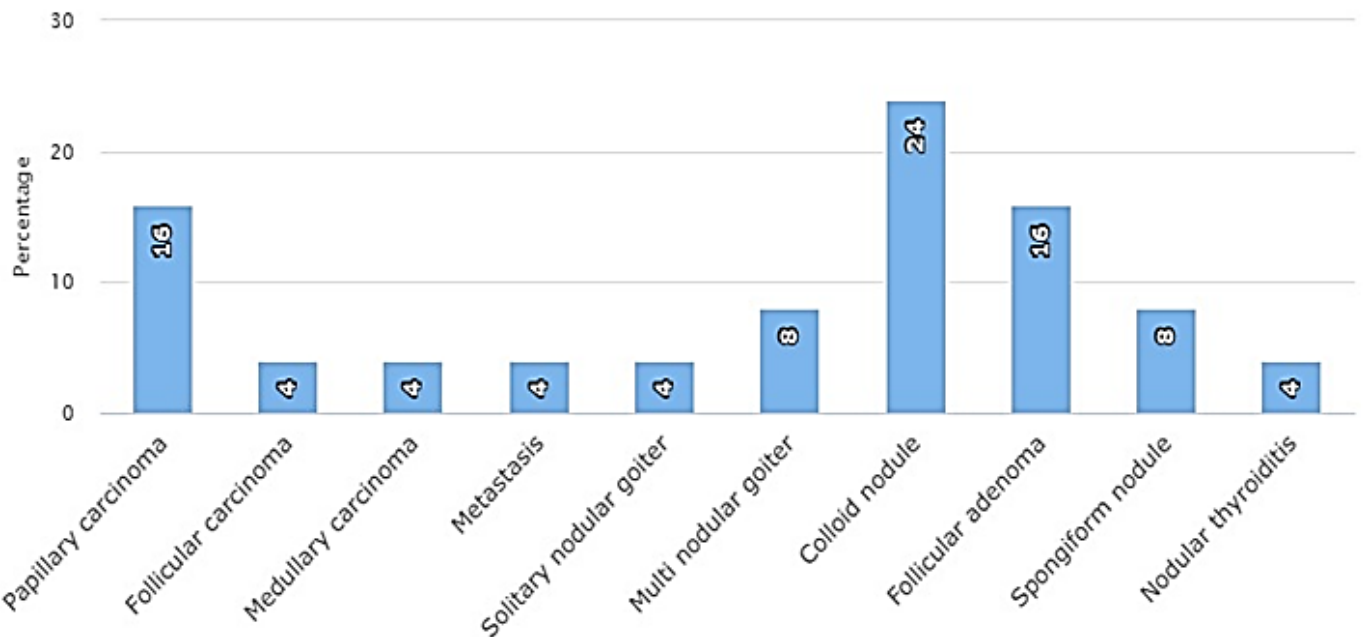

Fig (2) shows US diagnosis correlated with final diagnosis 



\section{Discussion}

This study was carried on patients who were referred from outpatient clinics to the radiology department of Met Gamer oncology center. A total number of 50 patient included in this study with incidental thyroid nodules on different radiological imaging's like MRI, CT and US that performed for assessment other regions not involved the thyroid and these patients underwent ultrasound examination of the thyroid that confirmed the presence of thyroid nodules. In the present study, as regard age, the mean age of study population is 44.7. As regard gender, the number of males were 8 (16\% of patients were males), while the number of females were 42 ( $84 \%$ were females). Mean patient age was $41.5 \pm 9.65$ and $49.3 \pm 10.4$ years in patients with benign and malignant nodules there was no statistical significant difference between the groups as regards the age, sex, however incidental thyroid nodules tends to be more common in females than males

The role of US in the detection of thyroid nodules has greatly increased, which normally goes unnoticed during routine clinical examination. As stated by the Incidental Thyroid Findings Committee that ITNs can be seen in 20 to $67 \%$ of ultrasound imaging, $25 \%$ of chest CT scans, and $18 \%$ of CT and MRI scans of the neck ( 8).

In this study the main symptoms were cough $36 \%$, LNS swelling 20\%, chest pain $12 \%$, hoarseness of voice $12 \%$, dyspnea $8 \%$ and fever $6 \%$ The CT or MRI study should first be evaluated for suspicious features associated with the ITN, including abnormal lymph nodes or signs of local invasion, neither of which is likely in a patient without thyroid-related symptoms. Abnormal lymph nodes are defined as enlarged nodes (9).

From 50 incidental nodules 36 nodules were benign nodules and 12 nodules were primary malignant and 2 nodules metastatic nodules

In a recent years, the high incidence of thyroid nodules has become particularly significant, primarily because of its gradually increasing annual prevalence and the increasing use of ultrasound. (10) Pathologically, most thyroid nodules are benign, with malignancy rate of approximately $5 \%$ to $7 \%$. Studies have shown that undifferentiated cancers that lead to a high mortality rate account for $1 \%$ to $2 \%$ of malignant nodules (11)

The majority of malignant nodules (especially those that are $<1 \mathrm{~cm}$ ) often have 
indolent behavior with positive prognoses. Therefore, many researchers have suggested that patients with thyroid nodules receive excessive care, and the significance of ultrasound has been questioned (12)

The term Incidental thyroid nodules are coined due to the presence of newly seen nodules on imaging such as ultrasound, computed tomography, magnetic resonance imaging and the more advanced positron emission tomography. (13)

Ultrasonography is the gold standard for study of thyroid nodules. It can detect small, multiple nodules and also isolate central or lateral neck lymphadenopathies. It provides accurate clarity in dimensions. It also characterizes nodules if suggestive of malignancy by highlighting irregular margins, absence of halo, micro calcifications. Characteristic features that could hint the prevalence of malignancy in a patient's history are previous head and neck irradiation, prevalence of rapid growth, dysphagia, and a family history of endocrine neoplasia or thyroid carcinoma. (13)

In the present study as regard ultrasound finding, we classified type of nodule as Solitary nodule, Multinodule and cystic nodule. Solitary solid nodule represented $(64 \%)$ of all patients while Soild
Multinodule was $12 \%$ of all patients and cystic nodule/s was $24 \%$ of all patients A slight difference was found compared to the study done by (14) where nodules were solitary in $55 \%$ and multiple in $45 \%$. However, in a study published 2018, the results indicate that $59.4 \%$ of the patients had multiple nodules while $40.6 \%$ had single nodules (13). The results of an Italian study (2) in which solitary nodules were found in $48.5 \%$ and multiple nodules in $51.5 \%$.

According to the study done in 2018 (13), ten $(31.25 \%)$ were reported to have solid nodules whereas two $(6.25 \%)$ of them were having cystic nodules. In contrast to our result, (15) cystic nodules were present in $49.4 \%$ and nodules of solid features were $33.6 \%$.

In the present study as regard nodular outline, 18 cases showed regular nodular outline $(72 \%)$ while irregular or ill-defined outline represented in $7(28 \%)$ patients Ill-defined margins were commonly seen in malignant thyroid nodules which was a specific criterion for differentiating malignant and benign nodules. (16). In Sudhir et. al., (13) study, out of 15 patients, eleven had well-defined margins while ill-defined margins were noted in four patients. According to that study (13), 
nodules that lost their smooth border are considered suspicious nodules and need further investigations to confirm the diagnosis.

In the present study, calcification was obtained in 12 case $(52 \%)$ which is divided to course or macrocalcification ( $24 \%$ of pt.) and microcalcification (28\% of pt.) while $(48 \%)$ of thyroid nodules showed on calcification

Sudhir et. al., (13) study, calcification (dense/ course) was a positive finding in the ultrasound of $5(35 \%)$ patients. Course calcification can be seen in malignant nodules as stated by (17).

All cases of microcalcifications were seen in papillary carcinoma with $100 \%$ specificity (16). Barring few cases of papillary and medullary carcinoma, majority of the macrocalcifications were seen in benign thyroid nodules (Adenomatous nodules) and showed insignificant $\mathrm{p}$-value. It was claimed that partially microcalcifications are the best predictor of malignancy, whereas other features seem less significant (18).

The additional presence of hyper-echoic foci of calcifications within the nodule further increases the likelihood of cancerapproximately three times the cancer risk for micro-calcifications and twice the risk for coarse calcifications (19). Microcalcifications have been reported to have specificity of $44-95 \%$ for thyroid cancer, and are particularly associated with papillary thyroid cancer. However, the sensitivity of micro-calcifications is low (26-59\%). Coarse macro-calcifications are not specific for malignancy, as they commonly occur in multinodular goiters. However, in situations where there is a single nodule containing coarse calcification, the risk of cancer can be as high as $75 \%$. (20)

In the present study, as regard doppler finding and its relation to malignancy confirmed by histopathological examination we found that all cases with malignant thyroid nodules showed increased central vascularity while benign tumors associated with decreased central vascularity .

A malignant nodule can also have an irregular shape with irregular edges (19). Further evaluation of the nodular vascularity should be performed with colour or power Doppler. Malignant lesions tend to demonstrate intra-nodular vascularity. In contrast, benign nodules have a peripheral rim of blood flow. When both intra-nodular and peripheral 
vascularity are present, the nodule is indeterminate

Although few studies reported contradictory results thyroid nodules are classified as non-vascular, peripheral vascular, central vascular, and mixed vascular according to the Doppler examination findings. Increased central vascularity is generally accepted as a supporting feature for diagnosis of malignancy in the literature $(\mathbf{2 1}, \mathbf{2 2})$

In our study, we found relationship between central vascularity and malignancy. Previous studies (5, 22, 23), did not find any relationship between intratumoural vascularity and malignancy, which is not in consistent with the results of our study. However, other study (24) says that intranodular vascularity is an important predictor of malignancy.

The sensitivity of Doppler US investigation is affected by settings of a wall filter, depth of the nodule and pulse repetition frequency (PRF), by variations of tissue attenuation, patient movement and lack of cooperation, swallowing or breathing motions. Pulsations of adjacent arterial structures may also affect Doppler US investigation. But recent studies suggested that parameters identified by color and spectral Doppler US may be able to differentiate between malignant and benign nodules (25)

In the present study, the cytological diagnosis of ultrasound-guided fine needle aspiration biopsy of the thyroid was as the following: colloid cyst (24\%), papillary carcinoma (20\%), follicular adenoma (16\%), solitary nodular goiter $(24 \%)$, multi nodular goiter $(8 \%)$, medullary carcinoma (4\%), and follicular carcinoma (4\%).

On US, thyroid nodules are depicted as discrete lesions, as they cause distortion of the homogeneous echo pattern of the thyroid gland. There are various characteristics on US that help to distinguish benign from malignant nodules. However, it is important to emphasize that the size and number of nodules are not reliable factors for disease differentiation. Evidence has shown that nodular size is not predictive of malignancy risk, and that nodular morphology, rather, is the more important criterion (26)

When assessing a thyroid nodule, it is important to note that malignant lesions are rare. The incidence of the disease is 2-4 cases per 100,000 persons per year. The most prevalent form of thyroid cancer is papillary thyroid cancer (75-80\%), followed by follicular (10-20\%), medullary $(3-5 \%)$ and anaplastic (1-2\%) thyroid 
cancers (27). In addition, the number of nodules is not associated with higher risk of cancer. Regardless of nodule quantity, the overall incidence of thyroid cancer is shown to be consistently between 9.2 and 13\% after FNAC (28) previous studies mentioned that solitary nodules, hypoechogenicity, irregular and lobulated margin, and micro calcification were significantly associated with malignancy $(\mathbf{2 9}, \mathbf{3 0}, \mathbf{5})$ In this study the US diagnosis was correlated with the final diagnosis based on histological examination in $92 \%$ of cases, 14 cases $28 \%$ were malignant and 32 cases $64 \%$ were benign.

From this study, it became clear that US is an important examination tool in evaluation of suspected incidental nodules. In addition to confirming the benign and malignant nodules US can help define site, size, and extent, number of nodules, echogenicity, calcification, margin, component and vascular involvement.

\section{Conclusion}

US is a valuable tool in assessment of incidentally detected thyroid nodules in others imaging features as it can show specific morphologic pattern in differentiating benign form malignant nodules. Ultrasonography can shorten the diagnosis time and reduce the burden on physicians. US diagnosis was correlated with the final diagnosis based on histological examination in most cases.

\section{References}

1- Hoang, J.K., Langer, J.E., Middleton, W.D. Managing incidental thyroid nodules detected on imaging: white paper of the ACR Incidental Thyroid Findings Committee. J Am Coll Radiol. 2015; 12: 143-150.

2-Papini E. Guglielmi R. Bianchini A. Crescenzi A. Taccogna S. Nardi F. et al . Risk of malignancy in nonpalpable thyroid nodules: predictive value of ultrasound and color-Doppler features. Journal of Clinical Endocrinology and Metabolism2002,87 (5);1941-1946..

3- Takashima S, Fukuda HNomura NKishimoto HKim TKobayashi $\mathrm{T}$ Thyroid nodules: reevaluation with ultrasound. J Clin Ultrasound. 1995;23179- 184

4- Horvath E, Majlis S, Rossi R . An ultrasonogram reporting system for thyroid nodules stratifying cancer risk for clinical management. J. Clin. Endocrinol. Metab. 2009;94 (5): 1748-51

5- Tamsel, G. Demirpolat, M. Erdogan, et Power Doppler US. patterns of vascularity and spectral Doppler US parameters in predicting malignancy in thyroid nodules Clin Radiol, 62 (2007), pp. 245

6- Henrichsen TL, Reading CC. Thyroid ultrasonography, part 2: nodules. Radiol Clin North Am 2011 49:417-424,v

7- Rago T, Vitti P, Chiovato L, Mazzeo S, De Liperi A, Miccoli P, et al : Role of conventional ultrasonography and color flow-Doppler sonography in predicting malignancy in "cold" 
thyroid nodules. Eur J Endocrinol 1998; 138:4146.

8- Hoang JK, Langer JE, Middleton WD . Managing Incidental Thyroid Nodules Detected on Imaging: White Paper of the ACR Incidental Thyroid Findings Committee. J. Am. Coll. Radiol. 12(2), 143-150 (2014).

9- Lehnert BE, Sandstrom CK,. Variability in management recommendations for incidental thyroid nodules detected on CT of the cervical spine in the emergency department. J Am Coll Radiol 2014;11:681-85

10- Kim TY, Shong YK. Active surveillance of papillary thyroid micro carcinoma : a mini-review from Korea. Endocrinol Metab (Seoul) 2017; 32:399-406.

11- Gregory A, Bayat M, Kumar V, Gregory A, Bayat M, Kumar V. Differentiation of benign and malignant thyroid nodules by using combpush ultrasound shear elastography: a preliminary two-plane view study. Acad Radiol 2018; 25:13881397.

12- Mendes GF, Garcia MR, Falsarella PM, Rahal A, Cavalcante Junior FA, Nery DR, et al. Fine needle aspiration biopsy of thyroid nodule smaller than $1.0 \mathrm{~cm}$ : accuracy of TIRADS classification system in more than 1000 nodules. $\mathrm{Br} \quad \mathrm{J}$ Radiol 2018; 91:20170642

13- Sudhir R V, Maher A, Abed E, Awad A, Syed $\mathrm{K}$, Issmaeledin $\mathrm{E}$, et al Incidental thyroid nodules an ultrasound screening of the neck region: prevalence \& risk factors Clin. Pract. (2018) 15(5), 873-879

14- Kamran M, Hassan N, Ali M . Frequency of thyroid incidentalomas in Karachi population. Pak. J. Med. Sci. 30(4), 793-797 (2014).
15- Moifo B, Tapouh JR, Fomekong SD, Djomou F, Wankie EM. Ultrasonographic prevalence and characteristics of nonpalpable thyroid incidentalomas in a hospital-based population in a subSaharan country. BMC Med. imaging. 17(1), 21 (2017).

16- Palaniappan, M. K., Aiyappan, S. K., \& Ranga, U. (2016). Role of Gray Scale, Color Doppler and Spectral Doppler in Differentiation Between Malignant and Benign Thyroid Nodules. Journal of clinical and diagnostic research : JCDR, 10(8), TC01-TC6

17- Kwak JY, Han KH, Yoon JH . Thyroid imaging reporting and data system for us features of nodules: A step in establishing better stratification of cancer risk. Radiology. 260, 892899 (2011)

18- Na DG, Baek JH, Sung JY, Kim JH, Kim JK, Choi YJ, Seo H: Thyroid imaging reporting and data system risk stratification of thyroid nodules: categorization based on solidity and echogenicity. Thyroid 2016; 26:562-572.

19- Frates MC, Benson CB, Charboneau JW . Management of thyroid nodules detected at US: Society of Radiologists in Ultrasound consensus conference statement. Radiology,237:794-800: 2005

20- Khoo ML, Freeman JL, Witterick IJ, Irish JC, Rotstein LE, Gullane PJ, et al. Underexpression of p27/Kip in thyroid papillary microcarcinomas with gross metastatic disease. Arch Otolaryngol Head Neck Surg. 2002;128(3):253-7

21-Algin O, Algin E, Gokalp G, Ocakoğlu G, Erdoğan C, Saraydaroglu O, et al. Role of duplex power Doppler ultrasound in differentiation between malignant and benign thyroid nodules. Korean J Radiol. 2010;11(6):594-602. 
22- Moon HJ, Kwak JY, Kim MJ, Son EJ, Kim

EK. Can vascularity at power Doppler US help predict

thyroid

malignancy? Radiology. 2010;255(1):260-69

23- Rosario PW, Silva AL, Borges MA, Calsolari

MR. Is Doppler ultrasound of additional value to gray-scale ultrasound in differentiating malignant and benign thyroid nodules? Arch Endocrinol Metab. 2015;59(1):79-83

24- Mohammadi A, Hajizadeh T. Evaluation of diagnostic efficacy of ultrasound scoring system to select thyroid nodules requiring fine needle aspiration biopsy. Int $\mathrm{J} \quad$ Clin Exp Med. 2013;6(8):641-48

25- Algin O, Algin E, Gokalp G, Ocakoğlu G, Erdoğan C, Saraydaroglu O, et al. Role of duplex power Doppler ultrasound in differentiation between malignant and benign thyroid nodules. Korean J Radiol. 2010;11(6):594-602.

26- Cooper DS, Doherty GM, Haugen BR, Kloos RT, Lee SL, Mandel SJ, et al. Revised American Thyroid Association management guidelines for patients with thyroid nodules and differentiated thyroid cancer. Thyroid. 2009;19(11):1167-214. doi: 10.1089/thy.2009.0110.

27- Jemal A, Murray T, Ward E, Samuels A, Tiwari RC, Ghafoor A, et al. Cancer statistics, 2005. CA Cancer J Clin. 2005;55(1):10-30. doi: 10.3322/canjclin.55.1.10.

28- Frates MC, Benson CB, Doubilet PM, Kunreuther E, Contreras M, Cibas ES, et al. Prevalence and distribution of carcinoma in patients with solitary and multiple thyroid nodules on sonography. J Clin Endocrinol Metab. 2006;91(9):3411-7. doi: 10.1210/jc.20060690

29- Lyshchik A, Drozd V, Demidchik Y, Reiners C. Diagnosis of thyroid cancer in children: Value of Gray-Scale and Power Doppler US. Radiology. 2005;235(2):604-13.

30- Fukunari N, Nagahama M, Sugino K, Mimura $\mathrm{T}$, Ito $\mathrm{K}$. Clinical evaluation of color Doppler imaging for the differential diagnosis of thyroid follicular lesions. World J Surg. 2004;28(12):12615.

To cite this article: Hesham E. Elsheikh, Ahmed E. Shalaan, Doaa ELsebaey. Role of Ultrasound and Color Doppler in Assessment of Incidental Thyroid Nodules. BMFJ 2021; 38 (Radiology):64-75., DOI:10.21608/bmfj.2020.32937.1276 